\title{
A shift in Clinical Learning Modalities-Telemedicine Training in UK Undergraduate Medical Students
}

\author{
Celion Tang ${ }^{1}\left(\mathbb{D} \cdot\right.$ Anjeevan Kaur Klair $^{1} \cdot$ Amir Hussain $^{2}$
}

Accepted: 22 December 2020 / Published online: 9 January 2021

(C) The Author(s) 2021

Dear editor,

As final year medical students having recently returned to clinical placements, we found Caplan et al.'s [1] article highly engaging. We agree that the use of simulation mannikins and online lectures are good teaching alternatives outside clinical settings. However, as echoed by recently graduated junior doctors [2], patient encounters are irreplaceable teaching opportunities. As mentioned by the author, such patient interactions train both diagnostic and communication skills. Replacing such teachings with inanimate mannikins neglects the fundamental communication training aspect of patient-encounters and therefore is not an entirely adequate teaching solution. Furthermore, NHS is shifting to telemedicine (online, telephone, or video call consultations) to minimize the risk of COVID-19 transmissions, altering the dynamics of clinical interactions $[3,4]$. We propose to incorporate telehealth training into our curriculum to both compensate for the lack of communication training from using mannikins and prepare the next wave of doctors for this emerging patientencounter platform.

Telemedicine, although effective and safe, has its challenges. It requires specific skillsets to overcome any technical or technological difficulties, at the same time building a good rapport with patients distantly. Clinicians without prior exposure to telehealth found it challenging to gather detailed history and establish appropriate working diagnoses. Certain communication skills, especially clear pronunciations and minimal body gestures are keys in assessing patients remotely

Celion Tang

celion.tang@student.manchester.ac.uk

1 Faculty of Biology, Medicine and Health, University of Manchester, Oxford Road, Manchester M13 9PL, UK

2 Manchester, UK
[5]. Additionally, students were more comfortable utilizing telemedicine after taught about the laws and ethics revolving telehealth applications [6].

In our own experiences, we found the demonstration of active listening with our body languages and eye contact was significantly limited, whereas verbal encouragements and summarizing were useful to build rapport remotely. Adapting to this digital form of patient interaction poses challenges especially considering undergraduate training has been primarily based on face-to-face encounters. As such, we believe that appropriate telehealth training is essential for medical students to familiarize and overcome the challenges in telecommunication discussed above. Although remote, it offers an alternative answer for face-to-face patient encounter communication training, not provided with the use of mannikins and without a concern for personal protective equipment (PPE).

In conclusion, this pandemic has called for a shift from the conventional delivery of clinical teachings. Some international medical schools had already implemented telemedicine training in their undergraduate curriculum [6]. Collaborative work between UK and overseas medical institutions would be beneficial to outline an effective telehealth training plan for UK medical students, that is in accordance to the available national guidelines on telehealth applications $[3,4,7]$.

Authors' Contributions All authors discussed, wrote and edited the manuscript. All authors read and approved the final manuscript.

Data Availability Not applicable

\section{Compliance with Ethical Standards}

Conflict of Interest The authors declare that they have no conflict of interest.

Ethics approval Not applicable

Consent to participate Not applicable 


\section{Consent for publication Not applicable}

\section{Code Availability Not applicable}

Open Access This article is licensed under a Creative Commons Attribution 4.0 International License, which permits use, sharing, adaptation, distribution and reproduction in any medium or format, as long as you give appropriate credit to the original author(s) and the source, provide a link to the Creative Commons licence, and indicate if changes were made. The images or other third party material in this article are included in the article's Creative Commons licence, unless indicated otherwise in a credit line to the material. If material is not included in the article's Creative Commons licence and your intended use is not permitted by statutory regulation or exceeds the permitted use, you will need to obtain permission directly from the copyright holder. To view a copy of this licence, visit http://creativecommons.org/licenses/by/4.0/.

\section{References}

1. Caplan J, Clements R, Chadwick C, Kadirgamar J, Morgan J, Rao A. Medical Education in 2020: Developing COVID Secure Undergraduate Hospital Placements. Medical Science Educator. Springer; 2020. p. 1-7. https://doi.org/10.1007/s40670-020-010802.

2. Choi B, Jegatheeswaran L, Minocha A, Alhilani M, Nakhoul M, Mutengesa E. The impact of the COVID-19 pandemic on final year medical students in the United Kingdom: a national survey. BMC Med Educ BioMed Central. 2020;20:206. https://doi.org/10.1186/ s12909-020-02117-1.

3. Specialty guides for patient management during the coronavirus pandemic Clinical guide for the management of remote consultations and remote working in secondary care during the coronavirus pandemic. NHS England and NHS Improvement. 2020. https://www. england.nhs.uk/coronavirus/wp-content/uploads/sites/52/2020/03/ C0044-Specialty-Guide-Virtual-Working-and-Coronavirus-27March-20.pdf. Assessed 16 October 2020.

4. COVID-19: video consultations and homeworking [Internet]. Available from: https://www.bma.org.uk/advice-and-support/covid19/adapting-to-covid/covid-19-video-consultations-andhomeworking. Assessed 16 October 2020.

5. Iancu AM, Kemp MT, Alam HB. Unmuting medical students' education: utilizing telemedicine during the COVID-19 pandemic and beyond. Journal of medical Internet research. NLM (Medline). 2020;22:e19667. https://doi.org/10.2196/19667.

6. Waseh S, Dicker AP. Telemedicine training in undergraduate medical education: mixed-methods review. J Med Internet Res. 2019. https://doi.org/10.2196/12515.

7. Remote consultations - GMC [Internet]. https://www.gmc-uk.org/ ethical-guidance/ethical-hub/remote-consultations. Assessed 16 October 2020.

Publisher's Note Springer Nature remains neutral with regard to jurisdictional claims in published maps and institutional affiliations. 